\begin{tabular}{|c|c|c|}
\hline 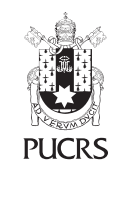 & $\begin{array}{l}\text { ESCOLA DE } \\
\text { HUMANIDADES }\end{array}$ & $\begin{array}{l}\text { Revista de Filosofia da PUCRS } \\
\text { Veritas, Porto Alegre, v. 65, n. 1, p. 1-4, jan.-mar. } 2020 \\
\text { e-ISSN: 1984-6746 | ISSN-L: 0042-3955 }\end{array}$ \\
\hline 10itp: $/ / \mathrm{dx}$ & $.0 \mathrm{rg} / 10.15448 / 1984-6746.2020 .1 .37006$ & \\
\hline
\end{tabular}

SEÇÃO: RESENHA

\title{
A ambiguidade das redes sociais na dominação oligopólica
}

\author{
Paulo J. Krischke ${ }^{1}$ \\ orcid.org/0000-0002-5957-037X \\ paulo.krischke@gmail.com
}

Recebido em: 3 fev. 2020. Aprovado em: 8 fev. 2020 Publicado em: 12 mai. 2020.

\section{(c) (1)}

Artigo está licenciado sob forma de uma licença Creative Commons Atribuição 4.0 Internacional.
ALBOM, Mitchell David. The First Phone Call from Heaven - a novel. New York: Harper Collins Books, 2014. 324p.²

Mitchell David Albom é escritor premiado, jornalista, roteirista, dramaturgo, radialista e músico dos Estados Unidos. Seus livros já venderam mais de 39 milhões de cópias em todo o mundo. Cinco de seus bestsellers focalizam os dilemas humanos das relações com a morte. Ele estudou literatura na Universidade de Detroit e, nessa cidade. iniciou sua carreira como jornalista e escritor. Nela, também patrocina três clínicas de atendimento a familias de baixa renda, e outras obras de assistência social, além de uma clínica do mesmo tipo nas Filipinas

Outro dia lendo um romance dos Estados Unidos (bestseller do The New York Times) sobre como a internet está ampliando (ambiguamente) a dominação oligopólica nos meios de comunicação, constatei que o livro dá um exemplo de como Brasil está presente nesse processo desde muito tempo. O livro de Mitch Albom The first phone call from heaven (New York: Little Brown Book, 2014, 182p.) menciona o conhecido (e pouco comentado) incidente quando Dom Pedro II interagiu com Alexander Graham Bell na feira internacional no primeiro centenário dos EUA, Philadelphia, 1876, sendo essa a primeira autoridade a experimentar fascinado uma mensagem telefônica de seu suposto inventor - que logo patentearia o presumido invento, apoiado nesse respaldo público oficial. Albom menciona, a seguir, os vários inventores que tentavam a patente do telefone na época, mas foram suplantados por esse apoio imperial brasileiro: Dom Pedro fez essa experiência acompanhando a comissão de juizes que premiou o melhor invento da feira.

Não por acaso, Dom Pedro era também celebrado naquele tempo como a única cabeça coroada da "Tríplice Aliança" (Brasil/Argentina/ Uruguai), na guerra da década anterior que dizimara a sangue-frio quase a totalidade da população masculina do Paraguai (1864-1870), ao mesmo tempo que cruelmente enganava com falsas promessas de liberdade os vastos contingentes de escravos de seu próprio exército e da marinha do Brasil. É claro que toda essa crueldade sanguinária

Universidade Federal de Santa Catarina (UFSC), Florianópolis, SC, Brasil.

Há uma tradução brasileira de Flavia Rossler, O Primeiro Telefonema do Céu, Rio de Janeiro, Editora Arqueiro, 2014, 244p, a qual não avaliamos nesta resenha. 
e mistificação autoritária combinam bastante com o clima político que temos vivido nestes últimos tempos no Brasil e no mundo. Contudo, cabe ao pensador restaurar a ambiguidade usual dos fatos, processos e instituições, para que os desvios e exageros de cada época e lugar possam ser devidamente avaliados, compensados, eventualmente corrigidos e no futuro evitados preventivamente. Pois, afinal de contas, nem todos são enfermos de sadomasoquismo em busca da autodestruição e do martírio; e a mais fervente religiosidade e misticismo podem também cultivar a tolerância, a ajuda mútua, e a solidariedade entre diferentes culturas, religiões e grupos sociais.

Mas, esse romance recente sobre as mídias sociais nos EUA denuncia com eficácia o amplo conluio entre interesses e agências públicas e privadas, na promoção conjunta dessas "fake news" religiosas e político-sociais que contaminam e manipulam o senso comum. Seu tema central é a controvérsia nacional e internacional que se estabelece em uma pequena cidade, típica do meio-oeste americano, com repercussões no noticiário das redes de televisão, quando vários cidadãos locais relatam receber do "além túmulo" chamadas telefônicas de parentes próximos já falecidos, trazendo mensagens tranquilizadoras sobre seu convivio no paraíso na presença de Deus, demais antepassados, anjos etc. A opinião pública favorável que recebem de todas as partes, veiculada pela grande mídia, gera um afuxo monumental de turistas para a cidade, que passa a exigir comprovação oficial sobre a veracidade dessas mensagens "do além".

Tal comprovação promete ser obtida em um "showmício" com milhares de participantes no estádio de esportes da cidade, quando novas mensagens do mesmo tipo serão recebidas em sequência, em "viva voz" pelos vários destinatários dos falecidos (e na presença dos vários pastores e sacerdotes locais). Sem querer estragar o suspense de desfecho desse romance, digamos apenas que o $\mathrm{FBI}$ surpreende ao final invadindo uma fazenda das proximidades, onde um ex-agente seu, especializado em espionagem como "hacker", consegue recriar e transmitir no anonimato, as vozes desses "falecidos" aos destinatários... Sem dúvida, um desses destinatários se dedica a revelar por sua conta e risco toda a fraude dessa tramoia - com apoio do delegado da polícia local (também ele um dos destinatários das "mensagens" originais).

A mensagem do livro, em suma: todos podemos (mesmo as autoridades) ser enganados legitimamente, mas entre nós, às vezes, surgem individuos paladinos da justiça, capazes de enfrentar a corrupção generalizada - mesmo quando esteja disfarçada/manipulada pela religião ou pela ordem pública.

A ficção das histórias sobre "cowboys", espiões e suspense policial, ficção científica etc. é de grande utilidade para avaliar o momento político, e as questões que afetam a preocupação das pessoas, e a moralidade pública e privada no âmbito do senso comum. Desde a eleição de Donald Trump nos Estados Unidos, temos visto profundas mudanças politicas internacionais, geralmente, caracterizadas por estratégias conservadoras e reacionárias, também em países da Europa e da América Latina. Com isso, as ciências humanas nem sempre percebem a ambiguidade que caracteriza esse processo. As obras de ficção costumam ser mais abertas que a reflexão jornalística ou científica, no sentido de que devem circular em um sentido mais amplo, de promoção do entretenimento entre grande número de consumidores dos bestsellers internacionais. Esse objetivo revela, muitas vezes, mudanças sutis na compreensão dos expectadores, que chegam, às vezes, a reforçar tendências maiores pré-existentes no plano subconsciente - tais como motivações de resistência e de inconformidade que podem eventualmente ganhar legitimidade concreta.

Esse romance sobre a ambiguidade das redes sociais e o controle oligopólico da política é inovador em muitos sentidos:

1. questionando, por exemplo, a onipresença da religião e a onipotência autoritária na vida das pessoas;

2. denunciando (outro exemplo) o autoritarismo das agências de vigilância e 
de controle militar nas esferas federal, regional e local;

3. revelando, também, principalmente, a vulnerabilidade das instituições estatais e dos meios de comunicação à invasão brutal e à esperta manipulação de dados pelos "hackers" individuais, criminosos, violadores, empresários e aventureiros de toda espécie.

Mas, a convergência fabricada entre as motivações morais/religiosas e a legitimidade autoritária já têm sido, muitas vezes, denunciadas antes, geralmente, sem muito sucesso - desde as invectivas de Sócrates/Platão contra a nefasta, mas persistente influência dos sofistas. Mesmo a ênfase das obras de um John Rawls ou de um Jürgen Habermas sobre o sentido plural, e às vezes, contraditório, das bases da legitimidade democrática nos países do Ocidente, tem sido negligenciada frequentemente, seja por sua "ingenuidade antropocêntrica", "pretensão evolucionista", ou "ilusão presentista" (como querem as críticas radical-feministas ou as dos chamados "pós-modernos". ${ }^{3}$ Habermas (1975, p. 76) é quem classicamente tem exposto essa lacuna, desde as crises de legitimidade dos anos 1960:

As estruturas motivacionais necessárias para a sociedade burguesa estão apenas incompletamente refletidas nas ideologias burguesas. As sociedades capitalistas sempre foram dependentes de condições culturais limitrofes que elas não podiam reproduzir por si mesmas; elas se alimentavam parasitariamente dos resquícios da tradição.

É importante enfatizar nesse ponto que Habermas utiliza os conceitos de tradição e de modernização no contexto dos estudos históricos sobre cultura e sociedade realizados pela "Escola de Frankfurt" - e, portanto, desde um ponto de vista inteiramente diferente da abordagem formal estrutural-funcionalista. O conceito de Habermas de ordem ou subsistema de legitimação foi construido a partir de sua ênfase na relação necessária entre legitimidade e "verdade de crença" (i.e., seu fundamento básico de legitimação na ordem motivacional). Ele afirmou sua posição em uma crítica das bem conhecidas tendências do funcionalismo estrutural a assimilar o conceito de legitimação de Weber àqueles de legalidade e adjudicação da lei.

[...] Se as decisões de acatamento obrigatório são legítimas, isto é, se elas podem ser tomadas independentemente do exercício concreto de coerção e ameaça manifesta de sanções, e podem ser regularmente implementadas mesmo contra os interesses dos afetados. então elas devem ser consideradas como o cumprimento de normas aceitas. Essa irrestrita validade normativa se baseia na suposição de que a norma poderia, se necessário, ser justificada e defendida contra a critica. E essa suposição não é, por sua vez, automática. É a conseqüência de uma interpretação que admite o consenso e que tem uma função moralmente reconhecida [...] (HABERMAS, 1975, p. 101).

As ambiguas relações da tradição com a modernidade, entre a religião, a política oficial e as linguagens da ficção e a da vida comum, devem ser continuamente reexaminadas, para seguir adiante em nossa trajetória.

\section{Referências}

ALBOM, Mitch. The First Phone Call from Heaven - a novel. New York: Harper Collins Books, 324 p.

CHILTON, Stephen. Situando o pós-modernismo na perspectiva do desenvolvimento moral-cognitivo, Civitas, Revista de Ciências Sociais, Porto Alegre, $\mathrm{n}$. 2, v. 2, p. 285-292, 2002. Tradução de Paulo Krischke. https://doi.org/10.15448/1984-7289.2002.2.102

HABERMAS, Jürgen. Legitimation Crisis. Boston: Beacon Press. Trad.: Thomas McCarthy, 1975.

RAWLS, John. 1992. A Justiça como Eqüidade: uma concepção política, não metafísica. Lua Nova, Revista de Cultura e Política, São Paulo, CEDEC, n.25, p. 25-59. Tradução de Regis Andrade. ttps://doi. org/10.1590/S0102-64451992000100003 


\section{Paulo J. Krischke}

Pesquisador Sênior do CNPq. Professor colaborador no PPGICH da Universidade Federal de Santa Catarina (UFSC, Florianópolis, SC, Brasil), e ex-professor visitante na Pontifícia Universidade Católica do Rio Grande do Sul (PUCRS). Recebeu recentemente recursos da Secretaria Estadual de Cultura de Santa Catarina para publicar suas memórias do exílio no Chile, Canadá e Europa que serão divulgadas em dramaturgia a comunidades populares da Grande Florianópolis, pelo centro cultural "Transformando pela Prática", do Rio Vermelho.

\section{Endereço para correspondência}

Paulo J. Krischke

Universidade Federal de Santa Catarina

Campus Reitor João David Ferreira Lima

Caixa Postal 476

Trindade, 88040-900

Florianópolis, SC, Brasil 